Плодоводство и виноградарство Юга России № 58(04), 2019 г.

УДК 634.85:631.524.84/.526.321:631.542.32

UDC 634.85:631.524.84/.526.321:631.542.32

DOI 10.30679/2219-5335-2019-4-58-88-103

DOI 10.30679/2219-5335-2019-4-58-88-103

ОЦЕНКА ФИЗИОЛОГИЧЕСКИХ

ПОКАЗАТЕЛЕЙ

И ПРОДУКТИВНОСТИ КЛОНОВ

ТЕХНИЧЕСКИХ СОРТОВ

ВИНОГРАДА В ЗАВИСИМОСТИ

ОТ РАЗРАБОТАННЫХ ЭЛЕМЕНТОВ

СОРТОВОЙ АГРОТЕХНИКИ*

\title{
ASSESSMENT OF PHYSIOLOGICAL INDICATORS AND PRODUCTIVITY OF CLONES OF TECHNICAL \\ GRAPES VARIETIES \\ DEPENDING ON DEVELOPED \\ ELEMENTS OF VARIETY \\ AGROTECHNICS
}

Бейбулатов Магомедсайгит Расулович

д-р с.-х. наук

начальник отдела агротехники

Beybulatov Magomedsaigit Rasulovich

Dr. Sci. Agr.

Head of Agrotechnology Department

Урденко Наталия Александровна

канд. с.-х. наук

Urdenko Natalia Aleksandrovna

Cand. Agr. Sci.

ст. научный сотрудник

отдела агротехники

Тихомирова Надежда Александровна

канд. с.-х. наук

ст. научный сотрудник

отдела агротехники

Буйвал Роман Алексеевич

канд. с.-х. наук

научный сотрудник

отдела агротехники

Senior Research Associate

of Agrotechnology Department

Tikhomirova Nadezhda Aleksandrovna Cand. Agr. Sci.

Senior Research Associate

of Agrotechnology Department

Buival Roman Alekseyevich

Cand. Agr. Sci.

Research Associate

of Agrotechnology Department

Федеральное государственное

бюджетное учреждение науки

«Всероссийский национальный

научно-исследовательский институт

виноградарства и виноделия

«Mагарач» $P A H »$,

Ялта, Республика Крыл, Россия

Federal State Budget

Scientific Institution

«All-Russian National

Research Institute

of Viticulture and Winemaking

«Magarach» RAS»,

Yalta, Republic of the Crimea, Russia

Выявление зависимостей между площадью листовой поверхности виноградного

The reveal of dependencies

between the leaf surface of a grape plant,

растения, нагрузкой куста, длиной обрезки плодовых лоз, с одной стороны, и ростом и плодоношением, с другой, раскрывает научные подходы для обоснования наиболее рационального подбора элементов сортовой агротехники. the load of the bush, the length of fruit vines pruning on the one hand, and growth and fruiting on the other hand, reveals the scientific approaches to well ground the most rational selection of elements of variety agrotechnics. As a result

*Работа выполняется в рамках Государственного задания Минобрнауки Российской Федерации (№ 0833-2015-0013 и 0833-2019-0021). 
В результате исследований установлено, что испытуемые клоны сортов винограда Алеатико 802, Мускат белый VCR-3, Каберне Совиньон R-5, с разработанными элементами сортовой агротехники, являются сильнорослыми и значительно превосходят сорта-эталоны. К концу вегетации их однолетние побеги вызрели от 83,6 до 94,8 \% своей длины.

Применение повышенного уровня нагрузок до 40-50 \% и удлинение плодовых лоз от 3 до 8 глазков на испытуемых клонах в условиях Южнобережной зоны Крыма при увеличении нагрузки на куст приводит к увеличению средней длины побега. Форма куста односторонний кордон на интродуцированных клонах обеспечивает наилучшее вызревание побегов. У клона сорта Каберне Совиньон $\mathrm{R}-5$, в сравнении с сортом-эталоном, уменьшение нагрузки на куст от 54 до 24 глазков не оказало влияния на силу роста куста. Наилучшим вызревание было у варианта с наименьшей нагрузкой на куст - 24 глазка при короткой обрезке плодовых лоз. Выделенные оптимальные параметры сортовой агротехники оказали положительное влияние на формирование индекса продуктивности (Сп) клонов сорта Алеатико 802 - от очень высокого уровня продуктивности до высокого, в сравнении с сортом-эталоном Алеатико (низкий и средний уровень значений данного критерия). У клона сорта Мускат белый VCR-3 при испытуемых формах куста индекс продуктивности сорта находился в пределах от средних до очень высоких значений, у сорта-эталона- средняя оценка Сп. У клона Каберне Совиньон R-5 - Сп от среднего до очень высокого уровня, у сорта-эталона уровень Сп оценён как очень низкий и низкий.

Ключевые слова: ВИНОГРАД, КЛОН, СОРТ, ЭЛЕМЕНТЫ СОРТОВОЙ АГРОТЕХНИКИ, ФОРМА КУСТА, НАГРУЗКА, ПРОДУКТИВНОСТЬ of the research, it was established that the tested clones of the Aleatiko 802, Muscat Bely VCR-3, Cabernet

Sauvignon R-5 varieties, with developed elements of variety agrotechnics, are vigorous and far exceed the standard varieties. To the end of the growing season, their annual shoots had ripened from 83.6 to $94.8 \%$ of their length.

The use of an increased level of loads up to $40-50 \%$ and elongation of fruit vines from 3 to 8 buds on the tested clones under the conditions of the Southern Coast Zone of the Crimea with increasing in the load on the bush leads to an increase in the average length of the shoot. The bush form as a one-sided cordon on the introduced clones provides the best maturation of the shoots. In the clone Cabernet Sovignon R-5, compared with the standard variety, reducing the load on the bush from 54 to 24 buds did not effect the growth vigor of the bush. The best ripening was for the variant with the lowest load on the bush -24 buds with a short pruning of fruit vines. The selected optimal parameters of variety agrotechnics had a positive effect the formation of productivity index $(\mathrm{Cp})$ of Aleatiko 802 clones - from a very high level of productivity to high, in comparison with the standard Aleatico variety (low and average values of this criterion). The clone of Muscat Bely VCR-3 with the tested forms of the bush index of varieties productivity ranged from medium to very high values, the standard variety had the average score of Cp. The Cabernet Sauvignon R-5 clone had $\mathrm{Cp}$ from medium to very high, the standard variety $\mathrm{Cp}$ is rated as very low and low.

Key words: GRAPEVINE, CLONE, VARIETY, ELEMENTS OF VARIETY AGROTECHNICS, BUSH FORM, LOAD, PRODUCTIVITY 
Введение. Виноградарство является одной из ведущих отраслей сельскохозяйственного производства юга России. Вегетативное состояние виноградного растения определяет его потенциальные возможности, которые регулируются элементами сортовой агротехники: нагрузкой куста и длиной обрезки плодовых лоз, формой куста и др. [1-5]. При помощи этих агротехнических приёмов растениям придают определённою конфигурацию, наиболее удобную для размещения листостебельного аппарата с высоким коэффициентом усвоения падающей на растения фотосинтетической активной радиации $[6,7]$.

Фотосинтетический аппарат растений, осуществляя сложную физиолого-биохимическую работу, меняется в зависимости от возраста, состояния растений и освещения, а также определяет формативные процессы, накопление отдельных продуктов и урожай, обладает высокой пластичностью и способностью приспосабливаться к различным условиям освещения $[8,9,10]$. Фотосинтетическая деятельность растений в ценозах характеризуется интенсивностью фотосинтеза листьев и качественным составом образующихся в них биопродуктов, ходом роста вегетативных органов и листовой поверхности, накоплением биомассы растений и распределением продуктов фотосинтеза между вегетативными и репродуктивными органами [8]. Регулирование хода фотосинтеза и движения ассимилятов лежит в основе ряда важных агротехнических мероприятий при выращивании винограда, которые оказывают влияние на работоспособность и продуктивность листьев, что в конечном итоге, обуславливает ростовые и репродуктивные проявления виноградной лозы, определяет урожай и его качество.

Значительное влияние на энергию фотосинтеза оказывает нагрузка побегами и гроздями. Различная нагрузка куста побегами и гроздями изменяет как интенсивность работы единицы листовой поверхности, так и продуктивность работы куста в целом $[3,6,7,11,12]$. Площадь листовой поверхности и ее ассимиляционные особенности определяют эффективность 
Плодоводство и виноградарство Юга России № 58(04), 2019 г.

использования растениями солнечной энергии, почвенной влаги и элементов питания. Развитие и деятельность листового аппарата определяются условиями выращивания и генотипом растений $[13,14,15]$.

Огромный вклад в развитие передовых промышленных технологий возделывания винограда внесли учёные и практики: К.Д. Стоев, Е.И. Захарова, А.Г. Амирджанов, Л.Т. Никифорова, Л.Ф. Шайтура, Н.А. Алиев, Г.А. Сарнецкий, В.П. Бондарев, Ш.Н. Гусейнов, Е.А. Егоров, К.А. Серпуховитина, А.И. Жуков, А.М. Аджиев, Л. Раваз, Н. Шаулис, Н.Т. Паныч, А.М. Мержаниан, А.И. Цейко, В.К. Дубинко, В.Ф. Карзов, И.В. Михайлюк, Р.Я. Согоян, Н.В. Матузок, Л.М. Малтабар и другие.

В исследованиях направленных агротехнических мероприятий, способствующих повышению урожайности и качества винограда, необходимо, прежде всего, воздействовать на агротехнические приёмы: схемы посадки виноградных кустов, способы ведения, формирования, нагрузки на куст, длины обрезки плодовых лоз побегами и урожаем и т.д. [16, 17]. Поэтому актуальность работы состоит в изучении характера проявления основных агробиологических признаков виноградного растения при применении изучаемых элементов сортовой агротехники.

Цель наших исследований состоит в сравнительной оценке показателей биологической и хозяйственной продуктивности клонов технических сортов винограда в зависимости от разработанной технологии возделывания.

Задачи исследований - установить влияние агротехнических приёмов (формы и нагрузки куста, длины обрезки) на рост, развитие, степень вызревания однолетних побегов у клонов европейских сортов винограда; определить влияние агроприёмов на показатели продуктивности куста в условиях Южнобережной зоны Крыма.

Объекты и методы исследований. Исследования проводились в условиях Южнобережной зоны Крыма (ЮБЗК) в 2017-2018 гг. Опытные 
Плодоводство и виноградарство Юга России № 58(04), 2019 г.

участки расположены на производственных массивах ФГУП «ПАО «Массандра», филиалы: «Ливадия», «Гурзуф», «Таврида». Вариант представлен 45 модельными кустами.

В качестве объектов исследований использовали насаждения винограда клонов сортов: Алеатико 802, Мускат белый VCR-3, Каберне Совиньон R-5. Опыт трёхфакторный полевой. У клонов Мускат белый VCR-3 и Алеатико 802 форма куста - АЗОС-1, схема посадки кустов - 3,0x1,25 м и односторонний горизонтальный кордон на среднем штамбе $(\mathrm{O} / \mathrm{K})$, схема посадки кустов - 3,0x1,5 м. У клона Каберне Совиньон R-5 и сортов-эталонов (Алеатико, Мускат белый и Каберне Совиньон) форма куста - двусторонний кордон на среднем штамбе (Д/К), при схеме посадки кустов 3,0х1,5 м.

Нагрузка на куст глазками у клона сорта Алеатико $802-15,18,12$ глазков, длина обрезки - 3 глазка; количество рожков - 5, 6 и 4. У сортаэталона Алеатико нагрузка на куст - 36 глазков, длина обрезки - 6 глазков; количество плодовых звеньев - 4 .

Нагрузка на куст глазками у клона сорта Мускат белый VCR-3 при форме куста O/K - 18, 33 глазка, длина обрезки - 6 и 8 глазков; количество плодовых звеньев - 2 и 3; при форме куста АЗОС-1 нагрузка на куст: 18, 23 и 26 глазков, длина обрезки - 3 глазка. У сорта-эталона Мускат белый нагрузка на куст 44 глазка, длина обрезки 8 глазков.

Нагрузка на куст глазками у клона сорта Каберне Совиньон R-5 - 24, 36, 36 и 54 глазка, длина обрезки - 3, 6, 3 и 6 глазков, соответственно. У сорта-эталона Каберне Совиньон нагрузка на куст - 54 глазка, длина обрезки - 6 глазков; количество плодовых звеньев - 6 .

Почвы на участках - коричневые, бурые горно-лесные.

В условиях ЮБЗК среднегодовая температура воздуха составила $+14,1{ }^{\circ} \mathrm{C}$ в 2017 г. и 14,9 ${ }^{\circ} \mathrm{C}$ в 2018 г. (среднемноголетнее значение 13,5 ${ }^{\circ} \mathrm{C}$ ), п. Никита. Сумма активных температур $\left(\geq+10{ }^{\circ} \mathrm{C}\right)-4072,5{ }^{\circ} \mathrm{C}, 4429,0{ }^{\circ} \mathrm{C}$ (среднемноголетнее значение $3751,0{ }^{\circ} \mathrm{C}$ ). Осадков выпало 533,1 мм 
и 784,0 мм (среднемноголетнее значение 619,6 мм) [18]. Таким образом, наблюдается повышение суммы активных температур за 2017-2018 гг. в среднем на 499,8 ${ }^{\circ} \mathrm{C}$. Вышесказанное подтверждает факт высокой тепло-, влагообеспеченности Южнобережной зоны Крыма.

Исследования проводились по общепринятым методикам и методическим разработкам по виноградарству $[19,20]$.

Обсужљение результатов. Сила роста является сортовым признаком. Ею руководствуются при определении схемы посадки кустов, нормы нагрузки и формировки куста, способов пространственного расположения частей куста. Проведённые нами исследования изучения силы роста куста и вызревания побегов по вариантам опыта подтверждают закономерность усиления ростовых процессов у изучаемых клонов сортов винограда вследствие уменьшения нагрузки куста глазками, при этом увеличивается средняя длина побегов и улучшается их вызревание (табл. 1).

В условиях ЮБЗК при увеличении нагрузки на куст от $25 \%$ до $50 \%$ на клоне сорта Алеатико 802; от 27 \% до 44 \% на клоне сорта Мускат белый VCR-3, при применении формы куста A3OC-1, сила роста куста не уменьшается, кусты характеризуются как сильнорослые. Наибольшие значения средней длины побегов у клона сорта Мускат белый VCR-3 как при форме куста односторонний кордон на среднем штамбе, так и при форме куста A3OC-1 была в вариантах с наименьшей нагрузкой куста глазками и составила 173,1 см и 187,4 см, что на 13,0 \% и 9,0 \% превосходит показатели вариантов с максимальной нагрузкой кустов. У клона сорта Каберне Совиньон R-5 при применении разработанных элементов сортовой агротехники кусты характеризовались как сильнорослые, у сорта-эталона - как среднерослые.

Все изучаемые клоны с разработанными для них элементами сортовой агротехники по показателю средняя длина побега превосходили сорта-эта- 
Плодоводство и виноградарство Юга России № 58(04), 2019 г.

лоны. Клон сорта Каберне Совиньон R-5 в сравнении с сортом-эталоном Каберне Совиньон превосходил его по силе роста.

Таблица 1 - Сила роста и вызревание прироста у клонов технических сортов винограда в зависимости от разработанной сортовой агротехники

\begin{tabular}{|c|c|c|c|c|c|}
\hline Вариант & $\begin{array}{c}\text { Нагрузка } \\
\text { куста, } \\
\text { гл. }\end{array}$ & $\begin{array}{c}\text { Длина } \\
\text { обрезки } \\
\text { плодовых } \\
\text { лоз, гл. }\end{array}$ & $\begin{array}{c}\text { Средняя } \\
\text { длина } \\
\text { побега, } \\
\text { см }\end{array}$ & $\begin{array}{c}\text { Категории } \\
\text { по силе } \\
\text { роста куста }\end{array}$ & $\begin{array}{c}\text { Вызревание } \\
\text { побегов, \% }\end{array}$ \\
\hline \multicolumn{6}{|c|}{ Клон сорта Алеатико 802} \\
\hline I & 18 & 3 & 196,7 & \multirow{4}{*}{$\begin{array}{l}\text { сильно- } \\
\text { рослые }\end{array}$} & 88,3 \\
\hline II & 15 & 3 & 202,1 & & 89,5 \\
\hline Контроль & 12 & 3 & 229,8 & & 93,0 \\
\hline $\begin{array}{c}\text { Сорт-эталон } \\
(\mathrm{O} / \mathrm{K})\end{array}$ & 36 & 6 & 161,1 & & 92,4 \\
\hline $\mathrm{HCP}_{05}$ & - & - & 26,2 & - & - \\
\hline \multicolumn{6}{|c|}{ Клон сорта Мускат белый VCR-3 } \\
\hline $\mathrm{I}(\mathrm{O} / \mathrm{K})$ & 33 & 8 & 150,6 & \multirow{6}{*}{$\begin{array}{l}\text { сильно- } \\
\text { рослые }\end{array}$} & 93,3 \\
\hline Контроль (О/К) & 18 & 6 & 173,1 & & 93,7 \\
\hline I (A3OC-1) & 23 & 3 & 170,6 & & 86,8 \\
\hline II (A3OC-1) & 26 & 3 & 165,5 & & 85,4 \\
\hline $\begin{array}{l}\text { Контроль } \\
\text { (АЗОС-1) }\end{array}$ & 18 & 3 & 187,4 & & 92,5 \\
\hline $\begin{array}{l}\text { Сорт-эталон } \\
(\mathrm{O} / \mathrm{K})\end{array}$ & 44 & 8 & 163,7 & & 94,8 \\
\hline $\mathrm{HCP}_{05}$ & - & - & 13,9 & - & - \\
\hline \multicolumn{6}{|c|}{ Клон сорта Каберне Совиньон R-5 } \\
\hline I & 24 & 3 & 165,2 & \multirow{4}{*}{$\begin{array}{l}\text { сильно- } \\
\text { рослые }\end{array}$} & 88,1 \\
\hline II & 36 & 6 & 173,1 & & 86,5 \\
\hline III & 36 & 3 & 160,3 & & 83,6 \\
\hline Контроль & 54 & 6 & 162,9 & & 81,4 \\
\hline $\begin{array}{l}\text { Сорт-эталон } \\
\text { (Д/К) }\end{array}$ & 54 & 6 & 138,9 & $\begin{array}{c}\text { средне-рос- } \\
\text { лые }\end{array}$ & 82,5 \\
\hline $\mathrm{HCP}_{05}$ & - & - & 15,3 & - & - \\
\hline
\end{tabular}

Примечание - у клонов сортов Мускат белый VCR-3 (при форме куста A3OC-1) и Каберне Совиньон R-5 проведена чеканка побегов.

Вызревание побегов - важное приспособительное свойство подготовки растений к зиме, степень которого является биологическим показателем состояния насаждений. Темпы, сроки и степень вызревания побегов обусловливаются, прежде всего, процессами роста.

В среднем за годы исследований степень вызревания побегов на изучаемых клонах сортов при применении разработанных элементов сортовой 
Плодоводство и виноградарство Юга России № 58(04), 2019 г.

агротехники можно охарактеризовать как хорошую: на клоне сорта Алеатико 802 увеличение нагрузки привело к незначительному уменьшению степени вызревания побегов от 3,8 \% до 5,1 \%. У клона сорта Мускат белый VCR-3 при форме куста односторонний кордон на среднем штамбе и увеличении нагрузки от 18 до 33 глазков на куст и длине плодовых стрелок 8 глазков не выявлено существенного влияния на степень вызревания. У того же клона при форме куста АЗОС-1 с увеличением нагрузки куста от 18 до 26 глазков вызревание побегов незначительно уменьшилось - от 6,2 \% до 7,7 \% и характеризовалось как хорошее. Необходимо отметить, что при форме куста односторонний кордон на среднем штамбе процент вызревания выше, вызревание проходило интенсивнее.

Лучшие показатели вызревания у клона сорта Каберне Совиньон R-5 при короткой обрезке плодовых лоз (3 глазка) было у варианта с наименьшей нагрузкой на куст - 24 глазка $(88,1 \%)$, у клонов сортов Алеатико 802 и Мускат белый VCR-3 наиболее полное вызревание отмечено при форме куста одноплечий горизонтальный кордон на среднем штамбе.

Продуктивность виноградных кустов напрямую связана с фотосинтезирующей поверхностью - площадью листовых пластинок, коррелирующуюся с показателями чистой продуктивности фотосинтеза (ЧПФхоз.) и хозяйственным коэффициентом (Кхоз.).

Интенсивность фотосинтеза листьев изменяется в зависимости от типа формирования. При форме куста более совершенной в отношении расположения вегетативных органов в пространстве листья меньше затеняют друг друга, в результате чего значительно увеличивается полезная площадь ассимиляционного аппарата, а это в конечном итоге приводит к повышению урожайности. К.Д. Стоев (1976) считает, что при одинаковой нагрузке и агротехнике формирование и обрезка винограда не вызывают существенных изменений фотосинтетической активности листовой поверхности, однако они оказывают глубокое влияние на распределение ассимилянтов и на этой 
Плодоводство и виноградарство Юга России № 58(04), 2019 г.

основе на формирование урожая и его качество, рост и вызревание побегов, обеспеченность корневой системы углеводами и т.д. [6].

Для учёта работы листового аппарата в связи с урожаем определяли фотосинтетический потенциал (ФП) и показатели чистой продуктивности фотосинтеза (ЧПФхоз). Полученные данные отражают преимущество изучаемых клонов сортов над сортами-эталонами на фоне разработанных элементов сортовой агротехники по вариантам опыта (табл. 2).

Таблица 2 - Влияние элементов сортовой агротехники на физиологические показатели и продуктивность клонов европейских сортов винограда

\begin{tabular}{|c|c|c|c|c|c|c|}
\hline Вариант & $\begin{array}{r}\text { Нагрузка } \\
\text { куста, гл. }\end{array}$ & $\begin{array}{c}\text { Длина } \\
\text { обрезки } \\
\text { плодовых } \\
\text { лоз, гл. }\end{array}$ & $\begin{array}{c}\text { Площадь } \\
\text { листовой } \\
\text { поверхности, } \\
\text { м }^{2}\end{array}$ & $\begin{array}{c}\text { ФП, } \\
\mathbf{M}^{2} \cdot \text { дней }\end{array}$ & $\begin{array}{c}\text { ЧПФхоз., } \\
\text { кг/га·сутки }\end{array}$ & Кхоз. \\
\hline \multicolumn{7}{|c|}{ клон сорта Алеатико 802} \\
\hline I & 15 & \multirow{3}{*}{3} & 5,7 & 701,0 & 2,20 & 0,47 \\
\hline II & 18 & & 6,5 & 810,5 & 2,30 & 0,47 \\
\hline Контроль & 12 & & 4,4 & 581,0 & 2,14 & 0,50 \\
\hline $\begin{array}{l}\text { Сорт-эталон } \\
(\mathrm{O} / \mathrm{K})\end{array}$ & 36 & 6 & 6,9 & 928,1 & 2,01 & 0,30 \\
\hline $\mathrm{HCP}_{05}$ & - & - & \begin{tabular}{l|l}
1,8 \\
\end{tabular} & 175,3 & 0,30 & - \\
\hline \multicolumn{7}{|c|}{ клон сорта Мускат белый VCR-3 } \\
\hline $\mathrm{I}(\mathrm{O} / \mathrm{K})$ & 33 & 8 & 5,0 & 718,6 & 3,58 & 0,41 \\
\hline Контроль $(\mathrm{O} / \mathrm{K})$ & 18 & 6 & 5,3 & 552,3 & 2,67 & 0,48 \\
\hline $\mathrm{I}(\mathrm{A} 3 \mathrm{OC}-1)$ & 23 & \multirow{3}{*}{3} & 5,7 & 540,1 & 3,57 & 0,43 \\
\hline II (A3OC-1) & 26 & & 5,6 & 688,1 & 3,81 & 0,38 \\
\hline $\begin{array}{l}\text { Контроль } \\
\text { (АЗОС-1) }\end{array}$ & 18 & & 5,0 & 494,5 & 3,14 & 0,43 \\
\hline $\begin{array}{l}\text { Сорт-эталон } \\
(\mathrm{O} / \mathrm{K})\end{array}$ & 44 & 8 & 5,2 & 785,5 & 4,19 & 0,46 \\
\hline $\mathrm{HCP}_{05}$ & - & - & \begin{tabular}{l|l}
0,5 & \\
\end{tabular} & 165,2 & 1,10 & - \\
\hline \multicolumn{7}{|c|}{ клон сорта Каберне Совиньон R-5 } \\
\hline $\mathrm{I}$ & 24 & 3 & \begin{tabular}{l|l}
4,9 &
\end{tabular} & 556,7 & 2,15 & 0,46 \\
\hline II & 36 & 6 & 7,5 & 785,8 & 2,40 & 0,44 \\
\hline III & 36 & 3 & 6,9 & 798,4 & 2,68 & 0,43 \\
\hline Контроль & 54 & \multirow[b]{2}{*}{6} & 7,4 & 884,3 & 3,00 & 0,38 \\
\hline $\begin{array}{l}\text { Сорт-эталон } \\
\text { (Д/К) }\end{array}$ & 54 & & 8,7 & 940,1 & 2,08 & 0,36 \\
\hline $\mathrm{HCP}_{05}$ & - & - & 1,7 & 213,8 & 0,45 & - \\
\hline
\end{tabular}

Установлено, что показатели ФП и ЧПФхоз. изучаемых клонов сортов увеличиваются прямопропорционально увеличению нагрузки куста. Для 
Плодоводство и виноградарство Юга России № 58(04), 2019 г.

клонов сортов, возделываемых в ЮБЗК, установлены следующие закономерности: показатели площади листовой поверхности куста, ФП и ЧПФхоз. клонов сортов находятся в прямой зависимости от нагрузки куста, длины обрезки плодовых лоз и формы куста. Это подтверждается статистически. В свою очередь значения показателей ЧПФхоз. у сортов-эталонов были ниже значений вариантов с повышенными нагрузками на куст у изучаемых клонов сортов винограда. Как результат Кхоз., который характеризует долю хозяйственной части урожая в общей массе годичной продукции при разработанных элементах агротехники выше, чем у сорта-эталона.

Так, у клона сорта Алеатико 802 при форме куста АЗОС-1 в вариантах опыта I-II с увеличением нагрузки на куст от 15 до 18 глазков площадь листовой поверхности куста увеличилась на 0,8 м². Значения фитометрических показателей у контрольного варианта находились ниже уровня значений опытных вариантов, а также значений сорта-эталона что подтверждается значениями дисперсионного анализа, $\mathrm{HCP}_{05}=1,8$.

У клона сорта Мускат белый VCR-3 при форме O/K с повышением нагрузки куста увеличилась площадь листовой поверхности за счёт увеличения количества побегов. При этом увеличилась доля слабо развившихся побегов на кусте. Площадь листовой поверхности изменялась в зависимости от нагрузки куста составила при форме куста О/К и нагрузке на куст 33 гл. - 5,0 м², а при форме куста АЗОС-1 и нагрузке на куст 23 гл. - 5,7 м² (увеличение данного показателя - 14,0\%).

Увеличение нагрузки кустов клона сорта Мускат белый VCR-3 повлияло на увеличение ФП растений. Наибольшие его значения в пересчёте на один куст были у вариантов с максимальной нагрузкой 33 и 26 глазков на

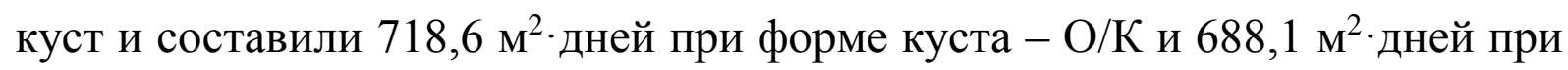
форме куста - АЗОС-1.

У клона сорта Алеатико 802 в разрезе всех испытуемых нагрузок при форме куста АЗОС-1 разница по показателю ЧПФхоз. между вариантами 
опыта и сортом-эталоном несущественна, $\mathrm{HCP}_{05}=0,30$. С увеличением нагрузки куста у клона сорта Мускат белый VCR-3 при форме A3OC-1, вследствие увеличения площади листовой поверхности, происходило увеличение показателя ЧПФхоз., средние значения которого составили соответственно 3,57 и 3,81 кг/га·сутки. Разница по данному показателю между изучаемыми формами куста $-6,7 \%$.

Наиболее объективным показателем, определяющим продуктивность фотосинтетической деятельности куста, является Кхоз., характеризующий долю хозяйственной части урожая в общей массе годичной продукции. Максимальные значения Кхоз. отмечены в вариантах с пониженной нагрузкой кустов глазками и при форме куста О/К составили 0,48 , а при форме куста АЗОС-1 - 0,43.

У клона сорта Каберне Совиньон R-5 при форме куста О/К с увеличением нагрузки на куст от 24 до 54 глазков были получены аналогичные результаты, которые подтверждают закономерность усиления ростовых процессов вследствие уменьшения нагрузки кустов глазками. Кусты с нагрузкой 24 глазка, где на куст было оставлено 4 звена, сформировали существенно меньшую площадь листовой поверхности с куста $\left(4,9\right.$ м $\left.^{2}\right)$ по сравнению с остальными вариантами опыта, где значения данного показателя составили от 6,9 м² до 7,5 м², что подтверждается значениями дисперсионного анализа, $\mathrm{HCP}_{05}=1,7$. Наибольшее значение ФП у варианта, где нагрузка куста была 54 глазка (контроль) - 884,3 м²·дней, что на 9,7-37,0 \% меньше значений данного показателя в разрезе вариантов опыта. Значения ЧПФхоз. в опытных вариантах на клоне сорта Каберне Совиньон R-5 при увеличении нагрузки от 24 до 36 глазков находились в пределах от 2,15 до 2,68 кг/га·сутки, что на 10,7-28,3 \% меньше по отношению к контрольному варианту, где была максимальная нагрузка на куст - 54 гл. Максимальные значения показателя Кхоз. получены в вариантах с пониженными нагрузками: 0,46-0,43, что на 13,2-21,1\% выше, чем у контрольного варианта и на 5,3\% выше сорта-эталона. 
Для достижения максимальной продуктивности агроценоза необходимо, прежде всего использовать приёмы агротехники и фитотехники, обеспечивающие оптимизацию среды и условий питания, размещения растений, их архитектуру. Потенциал более продуктивного сорта может быть реализован в полной мере тогда, когда агротехника оптимизирована и в качестве лимитирующего фактора урожайности выступает сам сорт. Низкий уровень агротехники и фитотехники нельзя компенсировать сортом.

Функции роста и плодоношения винограда взаимосвязаны и взаимообусловлены. На основании экспериментальных данных на рисунках 1-3 показано размещение индексов продуктивности клонов сортов (Сп) в сравнении с сортом-эталоном в зависимости от разработанных элементов сортовой агротехники при различных формах куста. Из рисунков видно, что с увеличением нагрузки снижается средняя масса грозди клонов сортов и, следовательно, Сп, связь обратная, описывается уравнением: $\mathrm{y}=0,6859 \mathrm{x}^{2}$ $39,855 x+681,59$ (клон сорта Алеатико 802), связь сильная, коэффициент детерминации $\mathrm{R}^{2}=0,948$.

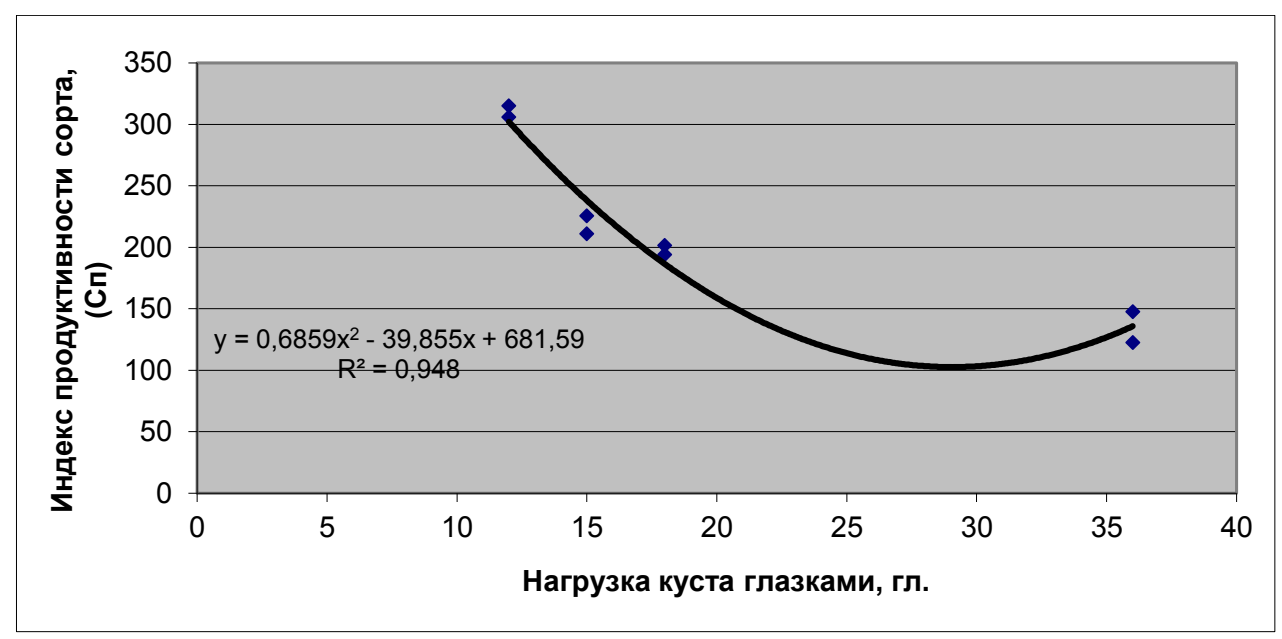

Рис. 1. Размещение индексов продуктивности у клона сорта Алеатико 802 в зависимости от разработанных элементов сортовой агротехники при форме куста АЗОС-1

У клона сорта Мускат белый VCR-3 при применении форм куста односторонний кордон и спиральный кордон АЗОС-1 данная связь средняя, коэффициенты детерминации имеют практически одинаковые значения при применении испытуемых форм куста $\left(\mathrm{R}^{2}=0,626\right.$ - при форме куста $\mathrm{O} / \mathrm{K}$, 
$\mathrm{R}^{2}=0,6044$ - при форме куста АЗОС-1). У клона сорта Каберне Совиньон R5 получена аналогичная обратная прямолинейная средняя связь, $\mathrm{R}^{2}=0,5902$. Следует отметить также, что показатель Сп у изучаемых клонов сортов выше значений показателя Сп у сортов-эталонов.

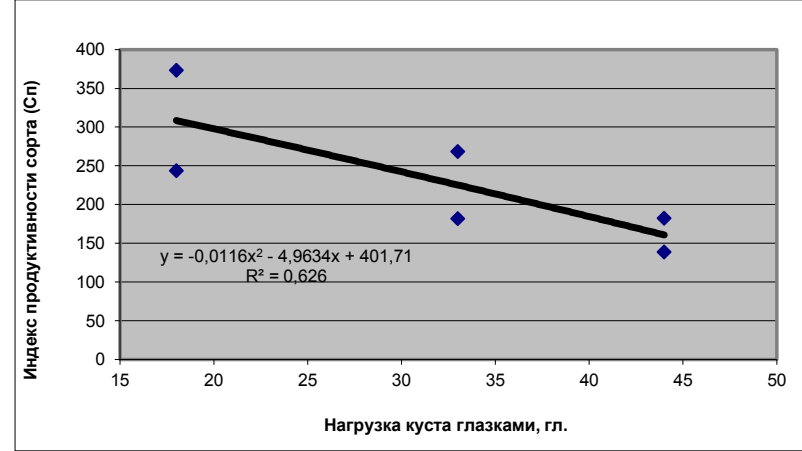

a)

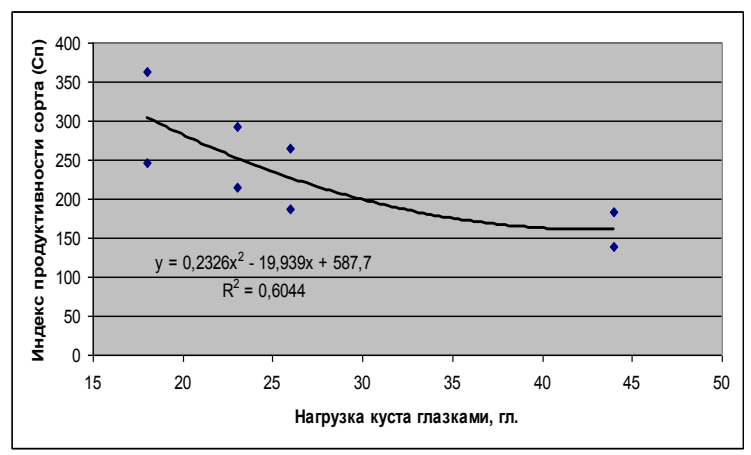

б)

Рис. 2. Размещение индексов продуктивности у клона сорта Мускат белый VCR-3 в зависимости от разработанных элементов сортовой агротехники:

a) при форме куста O/К, б) при форме куста АЗОС-1

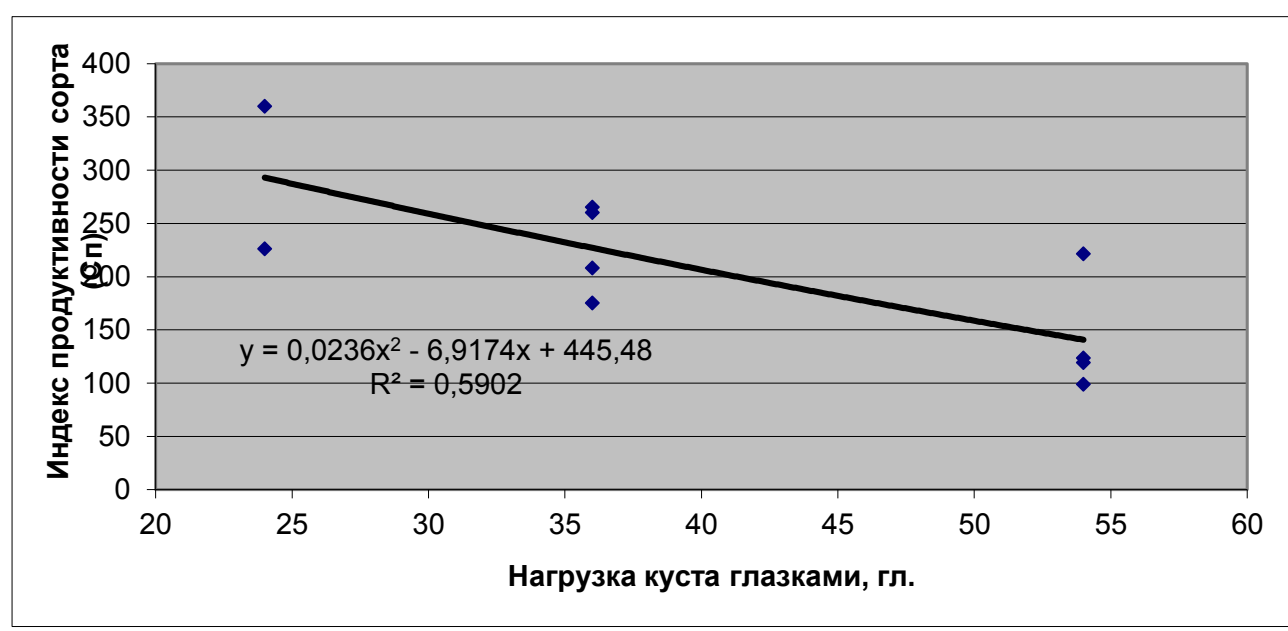

Рис. 3. Размещение индексов продуктивности у клона сорта Каберне Совиньон R-5 в зависимости от разработанных элементов сортовой агротехники при форме куста Д/К

Выделенные оптимальные параметры сортовой агротехники на исследуемых клонах сортов винограда оказали положительное влияние на формирование индекса продуктивности. Данный показатель можно оценить по шкале [10] и охарактеризовать его уровень у клона сорта Алеатико 802 как очень высокий и высокий, у сорта эталона уровень значений данного критерия низкий и средний. У клона сорта Мускат белый VCR-3 при применении 
Плодоводство и виноградарство Юга России № 58(04), 2019 г.

испытуемых форм куста характеристика Сп находилась в пределах от средних до очень высоких значений, у сорта-эталона индексы продуктивности получили среднюю оценку. У клона сорта Каберне Совиньон R-5 Сп в пределах от среднего до очень высокого, у сорта-эталона уровень показателя оценен как очень низкий и низкий.

Заключение. По результатам исследований установлено, что агротехнические факторы: нагрузка на куст, длина обрезки плодовых лоз и форма куста оказывают влияние на физиологические показатели и показатели продуктивности интродуцированных клонов европейских технических сортов винограда.

Таким образом, в условиях Южнобережной зоны Крыма высокие урожаи без ущерба для качества продукции могут быть получены при формах куста: односторонний кордон, двусторонний кордон и спиральный кордон АЗОС-1. Выбор формы куста исследуемых клонов технических сортов винограда будет зависеть от направления использования сырья.

Полученные данные по параметрам кроны и работе листового аппарата отражают преимущество формы куста односторонний горизонтальный кордон при максимальной нагрузке кустов глазками для клона сорта Мускат белый VCR-3 относительно формы куста A3OC-1.

Доказана возможность применения повышенных нагрузок 40-50 \% от исходной, не снижающих силу роста и степень вызревания прироста изучаемых клонов и сортов винограда. Форма куста односторонний горизонтальный кордон обеспечивает наилучшее вызревание прироста.

Авторы выражают благодарности: главному агроному ФГУП «ПАО «Массандра» Поляковой Т.Н., агрономам филиала «Ливадия» ФГУП «ПАО «Массандра» Назаренко И.И., филиала «Таврида» ФГУП «ПАО «Массандра» Соломеннику С.Н., филиала «Гурзуф» Мельнику М.Ю. за сбор материала. 


\section{Литература}

1. Ключникова Г.Н. Закономерность роста и плодоношения внутривидовых и межвидовых сортов винограда в зоне неукрывной культуры: автореф. дис. ... д-ра с.-х. наук: 06.01.07 / Ключникова Галина Николаевна. Краснодар, 2002. 48 с.

2. Carbonneau, A. Training system and wine quality: The misleading discussions about the role of vine spacingin 'lyre culture / A. Carbonneau // Rivista di Viticoltura e di Enologia, Conegliano. 1991. - V. 44 (4). -P. 329-333.

3. Guhgare, J.B. Studies on pruning of grape / J.B. Guhgare. Vitis, 1968, 2. P. 120-123.

4. Оценка агробиологических и хозяйственных признаков клона сорта винограда Мускат белый VCR-3 в условиях Южного берега Крыма / М.Р. Бейбулатов, Р.А. Буйвал, Н.А. Тихомирова, Н.А. Урденко // [Электронный ресурс] Плодоводство и виноградарство Юга России. 2018. № 51(3). С. 89-99. URL: http://journalkubansad.ru/pdf/18/03/09.pdf. DOI: 10.30679/2219-5335-2018-3-51-89-99 (дата обращения: 02.07.2019).

5. Продуктивность европейских клонов сортов в зависимости от сортовой агротехники в условиях Южнобережной зоны Крыма / М.Р. Бейбулатов, Р.А. Буйвал, Н.А. Тихомирова, Н.А. Урденко // «Магарач». Виноградарство и виноделие. Ялта, 2018, №1. C. $15-18$.

6. Стоев К.Д., Добрев С.И. Фотосинтез виноградной лозы и распределение ассимилятов в зависимости от формирования кустов // С.-х. биология. 1976. т. 11. № 4, с. $622-626$.

7. Cosmo, J. et coll. Bases scientifiques des systèmes de taille et de conduite haute de la vigne / J. et coll. Cosmo // Bull. O. I. V., 42. 1969, 455. -P. 5-17.

8. Амирджанов, А.Г. Солнечная радиация и продуктивность виноградника. Л.: Гидрометеоиздат, 1980. $207 \mathrm{c}$.

9. Фотосинтез / Д. Орт, Говинджи, Уитмарш Дж. [и др.]. М.: Мир, 1987. Т. 1. 728 с.

10. Kliewer, W.M. Influence of defoliation leaf darkening and cluster shading on the growth and composition of Sultana grapes / W.M. Kliewer, A.J. Antcliff// Vitis 9. 1970. - P. 291-298.

11. Алахвердиев Д.С., Мамедова Э.М. Продуктивность фотосинтеза листьев винограда в зависимости от нагрузки кустов // Виноделие и виноградарство СССР. 1981. № 8. C. 33-34.

12. Kauer, R. Vergleichende Untersuchungen zum integrierten und ökologischen Weinbau in ersten drei Jahren der Umstellung: Dissertation zur Erlangung des Doktorgrades / R. Kauer. Geisenheim, 1994. - 147 p.

13. Дурдыев, Б. Характер образования листовой поверхности и фотосинтетической деятельности хлопчатника при регулировании калийного питания // Молодой учёный. 2010. № 11. T. 2. C. 198-201.

14. Andricou, N. et coll. Regimul radiativ in piantatile viticoie din zona podgoriei Murfatlar / N. et coll. Andricou // Hidrotechnica. 1971. - N 2. -p. 101-108.

15. Downton, W.I.S., Grant W.I.R. Photosynthetic physiology of spur pruned and minimal pruned grapevines//Austral. Plant Physiol.- 1992.- Vol.19,№ 3.1. P.309-316.

16. Гордеев В.Н., Гусейнов Ш.Н., Чигрик Б.В. Современные агротехнические аспекты развития технологий возделывания винограда в РФ // Проблемы интеграции в мировой рынок винограда и вина: материалы межд. науч.-практ. конф. (10-11 ноября 2004 г.). Новочеркасск. 2005. С. 39-47.

17. Rudolf, Fox Wie reagirten die Rebsorten // Dtsch. Weinbau. 2003. - № 4. C. 34-37.

18. Расписание погоды. URL: //rp5.ru/docs/search/ru.

19. Доспехов, Б.А. Методика полевого опыта (с основами статистической обработки результатов исследований). М.: Колос, 1985. 377 с.

20. Методические рекомендации по агротехническим исследованиям в виноградарстве Украины / под ред. А.М. Авидзбы. Ялта: ИВиВ «Магарач», 2004. 264 с. 


\section{References}

1. Klyuchnikova G.N. Zakonomernost' rosta i plodonosheniya vnutrividovyh i mezhvidovyh sortov vinograda v zone neukryvnoj kul'tury: avtoref. dis. ... d-ra s.-h. nauk : 06.01.07 / Klyuchnikova Galina Nikolaevna. Krasnodar, 2002. 48 s.

2. Carbonneau, A. Training system and wine quality: The misleading discussions about the role of vine spacingin l'lyre culture / A. Carbonneau // Rivista di Viticoltura e di Enologia, Conegliano. 1991. - V. 44 (4). -P. 329-333.

3. Guhgare, J.B. Studies on pruning of grape / J.B. Guhgare. Vitis, 1968, 2. P. 120-123.

4. Ocenka agrobiologicheskih i hozyajstvennyh priznakov klona sorta vinograda Muskat belyj VCR-3 v usloviyah Yuzhnogo berega Kryma / M.R. Bejbulatov, R.A. Bujval, N.A. Tihomirova, N.A. Urdenko // [Elektronnyj resurs] Plodovodstvo i vinogradarstvo Yuga Rossii. 2018. № 51(3). S. 89-99. URL: http://journalkubansad.ru/pdf/18/03/09.pdf. DOI: 10.30679/2219-5335-2018-3-51-89-99 (data obrashcheniya: 02.07.2019).

5. Produktivnost' evropejskih klonov sortov $\mathrm{v}$ zavisimosti ot sortovoj agrotekhniki v usloviyah Yuzhnoberezhnoj zony Kryma / M.R. Bejbulatov, R.A. Bujval, N.A. Tihomirova, N.A. Urdenko // «Magarach». Vinogradarstvo i vinodelie. Yalta, 2018, №1. S. 15-18.

6. Stoev K.D., Dobrev S.I. Fotosintez vinogradnoj lozy i raspredelenie assimilyatov v zavisimosti ot formirovaniya kustov // S.-h. biologiya, 1976, t. 11, № 4, s. 622-626.

7. Cosmo, J. et coll. Bases scientifiques des systèmes de taille et de conduite haute de la vigne / J. et coll. Cosmo // Bull. O. I. V., 42. 1969, 455. -P. 5-17.

8. Amirdzhanov, A.G. Solnechnaya radiaciya i produktivnost' vinogradnika. L.: Gidrometeoizdat, 1980. $207 \mathrm{~s}$.

9. Fotosintez / D. Ort, Govindzhi, Uitmarsh Dzh. [i dr.]. M.: Mir, 1987. T. 1.728 s.

10. Kliewer, W.M. Influence of defoliation leaf darkening and cluster shading on the growth and composition of Sultana grapes / W.M. Kliewer, A.J. Antcliff// Vitis 9. 1970. - P. 291-298.

11. Alahverdiev D.S., Mamedova E.M. Produktivnost' fotosinteza list'ev vinograda v zavisimosti ot nagruzki kustov // Vinodelie i vinogradarstvo SSSR. 1981. № 8. S. 33-34.

12. Kauer, R. Vergleichende Untersuchungen zum integrierten und ökologischen Weinbau in ersten drei Jahren der Umstellung: Dissertation zur Erlangung des Doktorgrades / R. Kauer. Geisenheim, 1994. - 147 p.

13. Durdyev B. Harakter obrazovaniya listovoj poverhnosti i fotosinteticheskoj deyatel'nosti hlopchatnika pri regulirovanii kalijnogo pitaniya // Molodoj uchenyj. 2010. № 11. T. 2. S. $198-201$.

14. Andricou, N. et coll. Regimul radiativ in piantatile viticoie din zona podgoriei Murfatlar / N. et coll. Andricou // Hidrotechnica. 1971. - N 2. -p. 101-108.

15. Downton, W.I.S., Grant W.I.R. Photosynthetic physiology of spur pruned and minimal pruned grapevines//Austral. Plant Physiol.- 1992.- Vol.19,№ 3.1. P.309-316.

16. Gordeev V.N., Gusejnov Sh.N., Chigrik B.V. Sovremennye agrotekhnicheskie aspekty razvitiya tekhnologij vozdelyvaniya vinograda v RF // Problemy integracii v mirovoj rynok vinograda i vina: materialy mezhd. nauch.-prakt. konf. (10-11 noyabrya 2004 g.). Novocherkassk. 2005. S. 39-47.

17. Rudolf, Fox Wie reagirten die Rebsorten // Dtsch. Weinbau. 2003. - № 4. - C. 34-37.

18. Raspisanie pogody. URL: //rp5.ru/docs/search/ru.

19. Dospekhov B.A. Metodika polevogo opyta (s osnovami statisticheskoj obrabotki rezul'tatov issledovanij). M.: Kolos, 1985. 377 s.

20. Metodicheskie rekomendacii po agrotekhnicheskim issledovaniyam v vinogradarstve Ukrainy / pod red. A.M. Avidzby. Yalta: IViV «Magarach», 2004. 264 s. 